\title{
KOMPOSISI JENIS IKAN HASIL TANGKAPAN JARING INSANG HANYUT DI PERAIRAN SUNGAI LIAT, BANGKA
}

\author{
M. Rijal') \\ 1) Teknisi Litkayasa pada Balai Riset Perikanan Laut, Muara Baru-Jakarta \\ Teregristasi I tanggal: 5 Pebruari 2007; Diterima setelah perbaikan tanggal: 12 April 2007; \\ Disetujui terbit tanggal: 14 Maret 2007
}

\section{PENDAHULUAN}

Kabupaten Bangka merupakan salah satu daerah di kawasan propinsi terbaru Bangka Belitung menempatkan sektor kelautan dan perikanan sebagai prioritas dalam arah pembangunan di samping sektor lain seperti pertambangan (timah) dan pertanian (lada). Kekayaan sumber daya laut diprediksi mempunyai potensi cukup besar dan layak dikembangkan untuk menopang perolehan devisa bagi pendapatan asli daerah Kabupaten Bangka. Secara geografis, wilayah perairan yang berbatasan langsung dengan perairan Laut Cina Selatan memiliki potensi produktivitas dan kelimpahan sumber daya yang cukup tinggi. Sebagai daerah eksploitasi, besar ketersediaan stok ikan di daerah ini belum diketahui secara pasti, walaupun estimasi potensi diduga tinggi dengan tingkat pemanfaatan rendah. Hal ini, karena ketergantungan sumber data yang relatif terbatas. Berkaitan dengan rencana kegiatan pengkajian stok sumber daya perikanan di perairan Laut Cina Selatan, data primer di daerah Sungai Liat sangat penting untuk mendukung analisis pengkajian tersebut, karena di lokasi ini merupakan basis terbesar pendaratan ikan di Kabupaten Bangka. Sehubungan hal tersebut, maka pada tulisan ini akan diinformasikan hasil pengumpulan data primer yang diperoleh dari pengamatan kegiatan penangkapan ikan di laut bersama nelayan di perairan Sungai Liat.

\section{WAKTU, TEMPAT, ALAT, DAN CARA KERJA}

Pengumpulan data dilakukan pada bulan Juli 2003 di daerah Sungai Liat, Bangka dengan cara mengikuti kegiatan kapal nelayan di laut. Kapal yang diamati adalah kapal yang mengoperasikan alat tangkap jaring insang hanyut, lama di laut sekitar 5 hari. Alat yang dipergunakan timbangan, kertas ukur, keranjang sortir, dan alat tulis. Spesifikasi kapal dan alat tangkap di catat untuk mendapatkan data komposisi jenis hasil tangkapan dalam 1 trip. Seluruh hasil tangkapan dipisah (disortir) menurut jenis ikan, dihitung jumlah dan kemudian ditimbang bobot.

\section{HASIL PENGAMATAN}

\section{Armada Penangkapan}

Armada penangkapan ikan di Sungai Liat, Kabupaten Bangka pada umumnya kapal motor tempel terbuat dari bahan kayu dengan ukuran kapasitas rata-rata 5 GT, kisaran 2 sampai dengan 7 GT dengan tenaga penggerak 10 sampai dengan 40 PK. Jumlah kapal sampai dengan bulan Juni 2002 di Pelabuhan Perikanan Sungai Liat sekitar 250 armada. Jumlah tersebut belum termasuk yang berdomisili di daerah lain dalam wilayah Kabupaten Bangka yang pada kegiatan trip ini belum termonitor.

\section{Deskripsi Kapal dan Alat Tangkap}

Kapal yang digunakan adalah kapal motor (K. M. KARYA MAJU) terbuat dari bahan kayu kapasitas 5 GT dengan ukuran kapal sebagai berikut panjang 12 $\mathrm{m}$, lebar 2,5 m, dan dalam 1,5 m. Mesin Dompeng 20 PK. Jaring insang yang digunakan dikenal dengan nama jaring kembung yang mempunyai mata jaring 2,25 “, panjang jaring sekitar 30 PIS, dalam 6,5 depa.

\section{Cara Penangkapan}

Pengoperasian jaring dilakukan malam hari, nelayan berangkat ke laut sore hari, lama waktu menuju daerah penangkapan sekitar 6 sampai dengan 8 jam ke arah utara Pulau Bangka dengan kecepatan kapal 7 knot. Jaring ditawur hanya pada malam hari pada saat bulan gelap, jaring diangkat (haulling) kirakira 4 jam kemudian. Dalam 1 malam hanya dilakukan 1 kali tawur. Untuk mendapatkan penghasilan tambahan sambil menunggu jaring diangkat atau ditarik, anak buah kapal melakukan kegiatan memancing (pancing ulur) di sekitar lokasi pemberhentian kapal.

Hasil tangkapan disimpan dalam palka atau box fiber glass yang sudah terisi dengan es curah (es yang sudah dihancurkan). Dalam 1 bulan dilakukan 2 kali penangkapan atau 2 trip, lama waktu dalam 1 trip adalah 5 hari. 
Tabel 1. Hasil tangkapan dalam 1 trip kapal dengan menggunakan alat tangkap jaring insang di perairan Sungai Liat, Kabupaten Bangka

\begin{tabular}{|c|c|c|c|}
\hline No. & Jenis Ikan & $\begin{array}{c}\text { Jumlah } \\
\text { (ekor) }\end{array}$ & $\begin{array}{c}\text { Bobot } \\
\text { (kg) }\end{array}$ \\
\hline 1. & Hapau'Selar (Selaroides sp.) & 30 & 5 \\
\hline 2. & TambakiLentjam (Lethrinussp.) & 51 & 8,5 \\
\hline 3. & Hiu (Canchaminus sp.) & 2 & 2 \\
\hline 4. & Tongkol (Euthymnus aftinis) & 14 & 7 \\
\hline 5. & Parang-parang (Chirocentrus sp.) & 16 & 8 \\
\hline 6. & Gago/Manyung (Arius spp.) & 90 & 45 \\
\hline 7. & Tenggin (Scomberomerous spp.) & 28 & 14 \\
\hline 8. & TodakiJulung-julung (Fistularia sp.) & 21 & 7 \\
\hline 9. & SemariLemadang (Coryphaena hypourus) & 2 & 4 \\
\hline & Total & 254 & 100,5 \\
\hline
\end{tabular}

Jenis ikan yang tertangkap terdiri atas 9 jenis dengan bobot total 100,5 kg per trip per kapal yang didominasi oleh ikan manyung dan tenggiri (Scomberomerous spp.) (Tabel 1, Gambar 1).

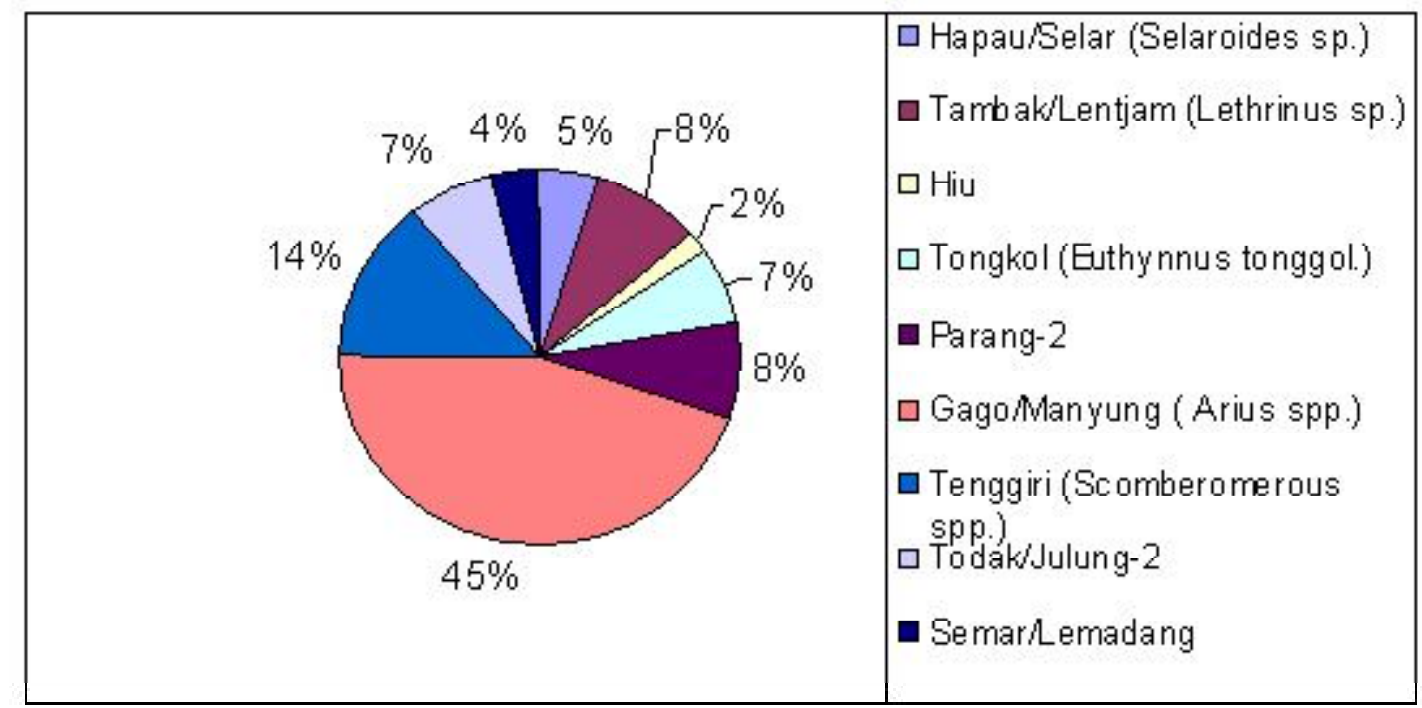

Gambar 1. Koposisi jenis hasil tangkapan jaring insang hanyut di perairan Sungai Liat, Bangka

\section{KESIMPULAN}

1. Kapal yang digunakan K. M..Karya Maju 5 GT dengan panjang $12 \mathrm{~m}$, lebar $2,5 \mathrm{~m}$, dalam $1,5 \mathrm{~m}$, dan mesin dompeng $20 \mathrm{PK}$.

2. Jaring insang yang digunakan dikenal dengan nama jaring kembung dengan mata 2,25", panjang jaring sekitar 30 PIS, dan dalam 6,5 depa.

3. Penangkapan dilakukan pada malam hari.
4. Daerah penangkapan tidak terlalu jauh dari pantai, sekitar 6 sampai dengan 8 jam perjalanan dari Sungai Liat dengan kecepatan kapal sekitar 7 knot.

5. Jaring ditawur saat gelap bulan, dalam 1 malam hanya 1 kali tawur.

6. Hasil tangkapan didominasi oleh ikan manyung (Arius thalassinus) 35,43\%, lentjam (Lethrinus spp.) $20,08 \%$, ikan selar (Selaroides sp.) dan tenggiri (Scomberomerous spp.) masing-masing $11,81 \%$ dan 11,02 . 